\title{
Positive and Negative Photolithographic Deposition of Titanium Dioxide from Photosensitive Titanium Complexes
}

\author{
Xin Zhang and Ross H. Hill* \\ $4 D$ Labs and Department of Chemistry, Simon Fraser University, \\ 8888 University Drive, Burnaby, British Columbia, Canada V5A $1 S 6$
}

\begin{abstract}
Lithographic deposition of titanium oxide films using photochemical metal organic deposition from titanium (IV) complexes is demonstrated in this paper. In this paper we explore the chemistry of thin films of titanium (IV) di-n-butoxide bis(2-ethylhexanoate), titanium (IV) di-n-butoxide bis(2-ethyl-2-hydroxybutyrate), titanium (IV) diisopropoxide bis(2,4-pentanedionate), and titanium (IV) diisopropoxide bis(ethyl acetoacetate). These complexes could all be prepared by ligand exchange reaction from the appropriate precursors. Thin films of each of these compounds could be cast by spin coating from solutions. All the complexes underwent photodecomposition to form titanium dioxide films although only titanium (IV) di-n-butoxide bis(2-ethylhexanoate) did so without the formation of an intermediate. Since all of the precursors were soluble negative lithography resulted in the direct deposition of titanium dioxide from these precursors. In contrast we were only able to demonstrate positive lithography on all the films except those constructed from titanium (IV) di-n-butoxide bis(2-ethylhexanoate). Positive lithography was conducted by exposing a region developing to remove film in the exposed regions followed by blanket exposure to convert the remaining regions to titanium dioxide. Patterns of titanium oxide with a feature size of 1 micron and a resolution of 1 micron were routinely achieved by both positive and negative photolithography. These precursors are also potential candidates for deep UV lithography in fabricating features of sub-50 nanometres.
\end{abstract}

Key words: film deposition, lithography, photochemistry, titanium complex

\section{Introduction}

In this contribution we describe the development of positive and negative lithography of titanium dioxide from a series of titanium precursor. The utility of thin films of titanium dioxide is associated with its high dielectric constant (up to $70[1,2]$ ), refractive index (up to $2.58[3,4])$, its photocatalytic capability $[5,6]$, and its high thermal and chemical stability [7]. The preparation and the properties of patterned titanium-containing films have been extensively investigated due to the potential of titaniumcontaining films in electronics, optics, and catalyst applications $[1,3,4,5]$. Patterned titaniumcontaining films are being used as plasma etchresistant layers pattern transfer onto underlying layers recently $[8,9]$.

We have been developing methods for the direct deposition of materials by photochemical metal organic deposition (PMOD) $[9,10,11]$. In this process, we deposit optical quality thin films of metal containing precursors, normally by spin coating. The precursors are designed such that exposure to light results in a photochemical reaction generating metal or metal oxide films from these metal complexes. The metal or metal oxide film is much more cohesive than the precursor molecular complexes. In the past we have made use of this greater cohesion to remove the unexposed molecular precursors by developing. The next result of this process is negative lithography.

In principle, however, both negative and positive lithography can be achieved by this method. We need only find a solvent able to remove the exposed region for positive lithography. The selection of a solvent is capable of removing the metal or metal oxide film by a wet 
development step, while, leaving, the unexposed region unchanged is not obvious. However, the exposure need not be complete, partial exposure may lead to a mixture which is more soluble than the unexposed film.

In this paper, we describe our efforts to develop precursor films which are able to be used in both negative and positive lithography. Previously, we reported the negative lithography of titanium oxide from $\left(\eta^{5}-\mathrm{C}_{5} \mathrm{H}_{5}\right)_{2} \mathrm{Ti}\left(\mathrm{N}_{3}\right)_{2}$ [ [12] and titanium (IV) diisopropoxide bis(2,4-petanedionate) [11,13]. In this contribution we build upon the latter compound. Here we make us of titanium alkoxide carboxylate and diketonates as precursor. We present the results of our investigation on the synthesis, thermal stability, photochemistry, positive and negative photolithography of thesetitanium complexes.

\section{Experimental}

Titanium (IV) diisopropoxide bis(2,4pentanedionate) $(75 \%$ in isopropanol), titanium (IV) isopropoxide (97\%), titanium (IV) n-butoxide $(99+\%)$, ethyl acetoacetate $(99 \%)$, 2-ethyl-2hydroxybutyric acid (99\%) and 2-ethylhexanoic acid (99+\%) were obtained from Aldrich Chemical Company Inc.. Four-inch silicon wafers were ptype (111) and were obtained from American Silicon Product B. V. Three-inch silicon wafers ntype (111) were purchased from Wafernet Inc..

\subsection{Synthesis of titanium (IV) complexes}

Titanium (IV) di-n-butoxide bis(2ethylhexanoate): Titanium (IV) n-butoxide (3.4521 g) was dissolved in hexanes $(10.0010 \mathrm{~g})$. Two molar equivalents of 2-ethylhexanoic acid (2.7870 g) were added to the resultant solution. This solution was stirred for 1 hour. The solvent was removed under reduced pressure using a rotary evaporator. The resulting residue was a yellowish liquid $(4.7850 \mathrm{~g})$.

Anal. Calc. for $\mathrm{C}_{24} \mathrm{H}_{48} \mathrm{O}_{6} \mathrm{Ti}: \mathrm{C}, 55.98 \% ; \mathrm{H}$, 9.96\%. Found: C, $59.99 \% ; \mathrm{H}, 10.07 \%$.

${ }^{1} \mathrm{H}$ Nuclear Magnetic Resonance (Bruker WP100SY $100 \mathrm{MHz}, \mathrm{CDCl}_{3}$ ) $\delta: 0.97 \mathrm{ppm}$ (triplet, $16 \mathrm{H},-\mathrm{CH}_{3}, \mathrm{~J}=13.0 \mathrm{~Hz}$ ), 1.17-2.01 ppm (multiplet, $20 \mathrm{H},-\mathrm{CH}_{2}-$ ) $2.01-2.61 \mathrm{ppm}$ (multiplet, $2 \mathrm{H}$, CHCOO-), 3.72 ppm (triplet, $2 \mathrm{H},-\mathrm{CH}_{2} \mathrm{O}-, \mathrm{J}=12.4$ $\mathrm{Hz}$ ), $4.14 \mathrm{ppm}$ (triplet, $1 \mathrm{H},-\mathrm{CH}_{2} \mathrm{O}-, \mathrm{J}=12.4 \mathrm{~Hz}$ ).

Thermal Gravimetric Analysis (Shimadzu TGA50): room temperature to $500{ }^{\circ} \mathrm{C}$ with a rate of $5^{0} \mathrm{C} / \mathrm{min}$, weight loss $81.41 \%$ (calculated based on the assumption that titanium (IV) di-n-butoxide bis(2-ethylhexanoate) decomposes to titanium dioxide: $83.37 \%$ ).

The complex titanium (IV) di-n-butoxide bis(2ethyl-2-hydroxybutyrate) was prepared in the same manner except that 2-ethyl-2-hydroxybutyric acid was used in stead of 2-ethylhexanoic acid and the solvent used was MIBK and anhydrous ethanol was added as a stabilizer. The compound titanium (IV) diisopropoxide bis(ethyl acetoacetate) was prepared in a similar manner except titanium (IV) n-butoxide was replaced with titanium (IV) isopropoxide and ethyl acetoacetate was used, instead of an acid, and the solvent used was hexane for the samples prepared for the photochemical studies and the positive patterning experiments. For the negative patterning experiments the solvent used was methyl isobutyl ketone.

2.2. Investigation on the photolysis of films formed from the titanium (IV) complexes

Titanium (IV) di-n-butoxide bis(2ethylhexanoate): The purified product $(0.1067 \mathrm{~g})$ was dissolved in hexanes $(0.8941 \mathrm{~g})$. The solution was spin coated on a sodium chloride $(\mathrm{NaCl}, \phi 32$ $\mathrm{mm} \times 4 \mathrm{~mm}$ ) disc at a spin speed of $3800 \mathrm{rpm}$ to make a sample. The sample was allowed to spin for 2 minutes. The sample was photolyzed in air with a low pressure mercury lamp (unfiltered, Model UVG-54, UVP Inc.) and monitored by a Fourier Transform Infrared (FTIR) spectrometer (Bomem MB120). The effect of photolysis for 0 , $15,30,45,60,81,112,150,201,260,330,420$, $540,720,1080,1800,3000,16800$, and 152700 seconds on the FTIR spectra of the sample was obtained.

A sample was prepared on a silicon chip $(\sim 15$ $\mathrm{mm} \times 15 \mathrm{~mm})$. The sample was then exposed with the low pressure mercury lamp. The effect of photolysis for $0,2,4,8,18,36$ and $766 \mathrm{~min}$ on the thickness and refractive index of the sample was evaluated with an Ex-Situ Phase Modulated Spectroscopic Ellipsometer with Integrated Imagery Camera from 260 to $2100 \mathrm{~nm}$ (Model: Horiba Jobin Yvon UVISEL UV-Visible-NIR). A Tauc Lorentz model was used for fitting the ellipsometry data.

The photolyzed sample was characterized by X-ray Diffraction (XRD) utilizing a Rigaku RAXIS RAPID-S diffractometer (Model No. 2163A101) and Auger Electron Spectroscopy (AES) utilizing a PHI scanning Auger microprobe (model 25-120) from Physical Electronics Industries Inc at $1 \mathrm{eV}$ resolution.

A second sample was prepared on a silicon 
chip. The sample was put in a quartz Schlenk tube connected to a vacuum line. The Schlenk tube was evacuated for 1 hour with a mechanical pump. The sample was photolyzed in the Schlenk tube with the low pressure mercury lamp. After photolysis for 4 hours, the Schlenk tube was sent for mass spectrometry (MS) analysis of the volatile products from photolysis.

Similar studies were carried out on the photolysis of titanium (IV) diisopropoxide bis(2,4pentanedionate), titanium (IV) diisopropoxide bis(ethyl acetoacetate), and titanium (IV) di-nbutoxide bis(2-ethyl-2-hydroxybutyrate).

\subsection{Lithography of films formed from the titanium (IV) complexes}

Titanium (IV) di-n-butoxide bis(2ethylhexanoate) $(0.0508 \mathrm{~g})$ was dissolved in methyl isobutyl ketone $(0.2056 \mathrm{~g})$ to make a precursor solution. The solution was spin coated onto a silicon chip and alloed to spin for $2 \mathrm{~min}$. The sample was covered with a chromium photo mask and exposed with an Oriel $\mathrm{Hg}$ (Ar) 6035 calibration lamp through the photo mask. The sample was exposed in air for 10 minutes. The sample was then mounted on the spin coater. Hexanes $(\sim 0.2 \mathrm{ml})$ was distributed on the sample from a pipette. The sample was spun at a speed of $3800 \mathrm{rpm}$ for 1 minute.

Lithography of films formed from other titanium (IV) complexes was carried out in a similar fashion. In the case of titanium (IV) di-nbutoxide bis(2-ethylhexanoate) the contact lithography was done on a 3 -inch wafer and the exposure was done with a Kasper 2001 aligner.

\section{Results}

3.1. Synthesis of titanium (IV) di-n-butoxide bis(carboxylato) complexes

A sample was made by combing two equivalents of 2-ethylhexanoic acid with one equivalent of titanium (IV) n-butoxide and allowing the mixture to react for one hour. The solvent was then removed under reduced pressure, yielding an oil. This oil was analysed and the carbon and hydrogen content was found to be consistent with the nominal formation of the product as titanium (IV) di-n-butoxide bis(2ethylhexanoate). The $\mathrm{CH}$ analysis indicated that the carbon content was low by ca. $5 \%$. This suggests that the sample may have undergone partial hydrolysis with loss of butanol and the formation of some hydroxyl ligand (or alternatively loss of butyl ether and the formation of bridging oxide).

The NMR analysis was consistent with the assignment to the product as titanium (IV) di-nbutoxide bis(2-ethylhexanoate). Interestingly the protons assigned as due to the methylene alpha to the oxygen appeared as two groups: one triplet at $3.72 \mathrm{ppm}$ and a second at $4.14 \mathrm{ppm}$. These we interpret as due to the formation of both cis and trans titanium (IV) di-n-butoxide bis(2ethylhexanoate). The structure of the anticipated cis and trans isomers are shown in Figure 1.

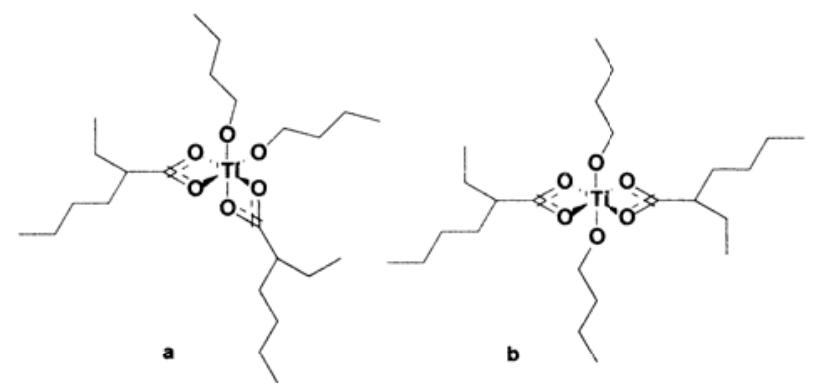

Figure 1 The anticipated cis (a) and trans (b) isomers of titanium (IV) di-n-butoxide bis(2-ethylhexanoate)

This result appears to confirm the formulation of the compound as titanium (IV) di-n-butoxide bis(2-ethylhexanoate). The formation reaction is apparently as given in Equation 1.

$\mathrm{Ti}\left(\mathrm{OC}_{4} \mathrm{H}_{9}\right)_{4}+2 \mathrm{HO}_{2} \mathrm{CCH}\left(\mathrm{C}_{2} \mathrm{H}_{5}\right) \mathrm{C}_{4} \mathrm{H}_{9} \rightarrow$ $\mathrm{Ti}\left(\mathrm{OC}_{4} \mathrm{H}_{9}\right)_{2}\left(\mathrm{O}_{2} \mathrm{CCH}\left(\mathrm{C}_{2} \mathrm{H}_{5}\right) \mathrm{C}_{4} \mathrm{H}_{9}\right)_{2}+2 \mathrm{HOC}_{4} \mathrm{H}_{9}$

Equation 1

Further evidence for this formulation was obtained from the effect of thermolysis on the sample. In this case thermal gravimetric analysis indicated the loss of $81.4 \%$ of the mass. This is consistent with decomposition according to the reaction shown in equation 2 . The mass loss was less than expected (ca $2 \%$ ).

$\mathrm{Ti}\left(\mathrm{OC}_{4} \mathrm{H}_{9}\right)_{2}\left(\mathrm{O}_{2} \mathrm{CCH}\left(\mathrm{C}_{2} \mathrm{H}_{5}\right) \mathrm{C}_{4} \mathrm{H}_{9}\right)_{2} \rightarrow \mathrm{TiO}_{2}$ + volatile by-products

Equation 2

This result would be expected if the complex had undergone partial loss of coordinated butoxide either as the ether resulting from the condensation of two molecules or as a result of hydrolysis. This is consistent with the result of $\mathrm{CH}$ analysis which suggested a lower than anticipated carbon content.

A titanium (IV) di-n-butoxide bis(2ethylhexanoate) solution was used to spin coat a silicon chip. The film produced was examined by optical microscopy and found to be free of optical no defects observed. The sample was also examined by XRD and no reflections associated with the film were observed. This indicates that 
the films cast of titanium (IV) di-n-butoxide bis(2ethylhexanoate) are amorphous.

The FTIR spectrum of a film of titanium (IV) di-n-butoxide bis(2-ethylhexanoate) was obtained and is shown in Figure 2. This consisted of absorption bands at 2961, 2936, 2876, and 2862 $\mathrm{cm}^{-1}$, associated with $\mathrm{CH}$ stretching vibrations. The broad absorption band at $1512 \mathrm{~cm}^{-1}$ is assigned to $v_{\text {as }}\left(\mathrm{CO}_{2}\right)$ while the absorbances at 1462 and $1424 \mathrm{~cm}^{-1}$ are due to $v_{\mathrm{s}}\left(\mathrm{CO}_{2}\right)$ of the 2ethylhexanoate ligand. Additional bands at lower energy are apparent and are combination modes associated of C-H and C-C motions in the ligands. The weak absorption bands at 1115 and $1101 \mathrm{~cm}^{-1}$ are assigned to $v(\mathrm{CO})$ of the un-substituted nbutoxide groups.

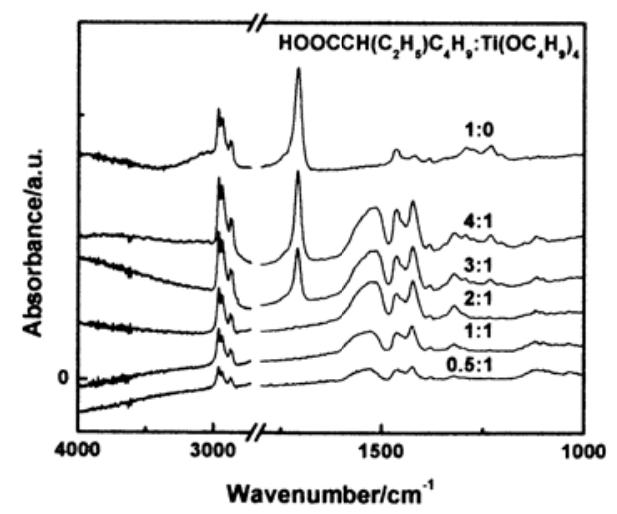

Figure 2 The FTIR spectra of samples formed by spin coating solutions prepared with titanium (IV) n-butoxide and $0.5,1,2,3$, and 4 molar equivalents of 2 ethylhexanoic acid and allowed to react for 60 minutes and the FTIR spectrum of a 2-ethylhexanoic acid sample

The separation between the antisymmetric and symmetric $\left(\mathrm{CO}_{2}\right)$ stretching vibrations is indicative of the nature of the bonding between the metal and coordinated carboxylate [14]. The separation found in this complex is consistent with bidentate coordination. This indicates that the solution structure and the structure in the film are probably the same.

The structure of the compound in the film is presumed to be similar to the solution structure. A mixture of the cis and trans isomers is presumably present in this sample, and it is that mixture which is responsible for the broadening of the $v_{a s}\left(\mathrm{CO}_{2}\right)$ stretching.

Similar samples were prepared by combining 1 molar equivalent of titanium (IV) n-butoxide with $0.5,1,3$, and 4 molar equivalents of 2ethylhexanoic acid for 60 minutes. These samples were used to coat silicon chips and the FTIR of each of the produced films was obtained. These are presented in Figure 2.

The FTIR spectra of the sample prepared with three equivalents 2-ethylhexanoic acid consisted of all the bands associated with titanium (IV) di-nbutoxide bis(2-ethylhexanoate) plus bands associated with uncoordinated 2-ethylhexanoic acid. The relative intensity of the bands indicated that the result was consistent with the sample being a mixture of titanium (IV) di-n-butoxide bis(2-ethylhexanoate) and uncoordinated 2ethylhexanoic acid.

A similar spectrum was obtained from a sample where the number of equivalents of 2ethylhexanoic acid was 4 . Once again the results was found to be consistent with the formation of a mixture of titanium (IV) di-n-butoxide bis(2ethylhexanoate) and uncoordinated 2ethylhexanoic acid.

These results indicate that excess 2ethylhexanoic acid does not react with the product titanium (IV) di-n-butoxide bis(2-ethylhexanoate). These results are consistent with the studies of others $[15,16]$, who observed that the only the disubstituted complexes could be prepared when the incoming ligand was bidentate.

The sample with only 0.5 equivalents of 2 ethylhexanoic acid also differed from the sample with 2 equivalents. In this case the ratio of the bands associated with the coordinated 2ethylhexanoate ligands are similar to that found in the disubstituted complex, titanium (IV) di-nbutoxide bis(2-ethylhexanoate). This result suggests that the product in the presence of 0.5 equivalents is a mixture of titanium (IV) di-nbutoxide bis(2-ethylhexanoate) and unreacted titanium n-butoxide. This interpretation should be treated with caution, as the intensity ratio could be coincidental. It is known in other systems that monosubstitution is possible [15].

Similar results are found when 1 equivalent of the 2-ethylhexanoic acid is added to titanium nbutoxide. The ratio of the intensities of bands is consistent with the formation of titanium (IV) di-nbutoxide bis(2-ethylhexanoate) and unreacted titanium n-butoxide.

The FTIR of samples were also studied to determine if there was an effect associated with varying the reaction time. In addition to the sample prepared following 60 minutes reaction samples were prepared following 1 and 1440 minutes reaction. The FTIR spectra of these samples were not distinguishable from the sample prepared following 60 minutes reaction. This indicated that 
the reaction was substantially over in the first minute.

Similar studies were done on the ligand exchange reaction used to produce titanium (IV) di-n-butoxide bis(2-ethyl-2-hydroxybutyrate). The results of this study were consistent with the study of titanium (IV) di-n-butoxide bis(2ethylhexanoate). A rapid exchange reaction occurred which resulted in the formation of the disubstituted complex titanium (IV) di-n-butoxide bis(2-ethyl-2-hydroxybutyrate). The addition of additional ligand did not result in additional substitution being observed.

The only significant deviation between the two systems was that, while the FTIR spectrum of titanium (IV) di-n-butoxide bis(2-ethylhexanoate) was consistent with bidentate coordination of the 2-ethylhexanoate ligand, a different result was found for titanium (IV) di-n-butoxide bis(2-ethyl2-hydroxybutyrate). In this case, the separation of the symmetric and antisymmetric bands of the carboxylate groups were indicative of bridging coordination. This indicates that the film was composed not of simple monomers but rather that there was association and the formation of a polymer within the thin film.

\subsection{Photochemistry of thin films of the substituted} titanium (IV) alkoxide precursors
3.2.1.
Titanium
(IV)
di-n-butoxide

bis(carboxylato) complexes

A film of titanium (IV) di-n-butoxide bis(2ethylhexanoate) was prepared by spin casting. The FTIR of this sample was obtained and then the sample was exposed with $254 \mathrm{~nm}$ light. The FTIR spectrum was obtained. The intensity of all absorption bands in the spectrum decreased as a result of this exposure. This process was repeated to and the family of spectra is shown in Figure 3. Each photolysis resulted in a further decrease in the absorption bands associated with titanium (IV) di-n-butoxide bis(2-ethylhexanoate). By a total photolysis time of 1800 seconds the absorption bands associated with titanium (IV) di-n-butoxide bis(2-ethylhexanoate) are largely lost.

As the phololysis progressed, it is also apparent that a weak band appears at $3370 \mathrm{~cm}^{-1}$. This new absorption band continues to grow throughout the photolysis and its growth in concomitant with the loss of absorption bands of titanium (IV) di-nbutoxide bis(2-ethylhexanoate). This band is indicative of the formation of hydroxyl groups in or on the surface of the film.

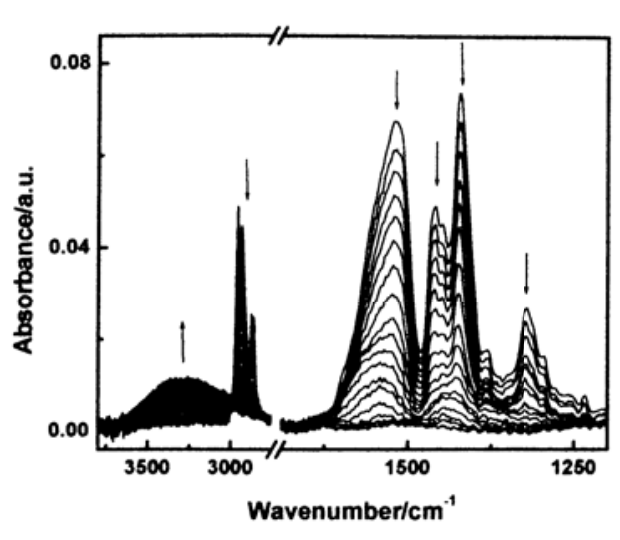

Figure 3 The effect of photolysis for $0,15,30,45,60$, $81,112,150,201,260,330,420,540,720,1080,1800$, 3000,16800 , and 152700 seconds on the FTIR spectrum of a sample of titanium (IV) di-n-butoxide bis(2-ethylhexanoate) on a $\mathrm{NaCl}$ disc

The film resultant from photolysis was investigated by XRD. No reflections observed indicated that the product film was amorphous.

The film was also investigated by Auger electron spectroscopy. The results were interpreted using sensitivity factors available in the literature [17]. The surface consisted of titanium (19\%), oxygen (66\%) and carbon (14\%). The surface was then cleaned by sputtering with argon ions for both 12 and 60 seconds. The effect of sputtering was a reduction of carbon contamination, and after 60 seconds no further carbon was observed. The results are summarized in Table 1.

Table 1 AES analysis of a photolyzed titanium (IV) din-butoxide bis(2-ethylhexanoate) sample

\begin{tabular}{llll}
\hline Element & surface & $12 \mathrm{~s}$ sputter & $60 \mathrm{~s}$ sputter \\
\hline Titanium (\%) & $19.4 \pm 1.8$ & $21.1 \pm 1.9$ & $22 \pm 2$ \\
Oxygen (\%) & $66.3 \pm 1.6$ & $70.4 \pm 1.6$ & $77.6 \pm 1.8$ \\
Carbon (\%) & $14 \pm 4$ & $9 \pm 5$ & 0 \\
Ti:O & $1: 3.4$ & $1: 3.3$ & $1: 3.5$ \\
\hline
\end{tabular}

The Auger electron spectroscopy suggested a ratio of oxygen to titanium to be 3.5 to 1 ; higher than would be expected for titanium dioxide. This result would however be consistent with the formation of a mixed oxide hydroxide of titanium. This result is not definitive, however, due to the potential effects of preferential sputtering. The FTIR data also indicated the presence of hydroxyl groups on the surface but this does not allow a quantitative explanation. In order to investigate further the surface composition we explored the effects of crystallization of the sample. 
A sample of amorphous titanium dioxide, prepared as above was annealed in an oven at $500{ }^{\circ} \mathrm{C}$ for an hour. The resultant sample was investigated by XRD. Diffraction peaks were observed at angles $(2 \theta)$ of $25.39^{\circ}, 38.19^{\circ}, 48.23^{\circ}$, $54.99^{\circ}, 62.71^{\circ}$, and $75.41^{\circ}$.

The presence of diffraction peaks in the XRD spectrum confirmed that the amorphous sample had crystallized. The data was compared with the expected diffraction spectra of several phases of titanium dioxide. The data was in agreement with the expected reflections for anatase whose reflections are found at $25.33^{\circ}(101), 37.83^{\circ}(004)$, $38.60^{\circ}(112), 48.08^{\circ}(200), 53.94^{\circ}(105), 55.11^{\circ}$ (211), $62.75^{\circ}(204)$, and $75.12^{\circ}(215)$ [18].

The Auger results of the thin film of anatase were then obtained under the same conditions as was used above for the amorphous sample. The Auger electron spectrum was analysed and the ratio of oxygen to titanium in the sputtered sample was found to be 3.5:1.

This ratio is consistent with the measured ratio in the amorphous film indicating that both films have the same composition. As a result of this experiment we believe that the amorphous film is titanium dioxide.

The photoproducts, which escaped the film, were investigated by mass spectroscopy. In this case the thin film of titanium (IV) di-n-butoxide bis(2-ethylhexanoate) on a silicon chip was exposed inside of a sealed cuvette under vacuum. The head space above the sample was then injected into a MS and the products analysed. The result of this analysis is presented in Table 2.

Clear evidence is found for the presence of carbon dioxide, heptane and heptene. Fragments consistent with the presence of butane, propane and carbon monoxide are also identified in Table 2. These latter fragments and their identification should be treated with caution as the fragments may also arise from the fragmentation of the larger molecules already identified.

The results above are all consistent with the general reaction provided as Equation 3. The photolysis results in the loss of both the 2ethylhexanoate ligand and the n-butoxide. Since no intermediate was observed in the FTIR, we cannot determine the temporal sequence of this loss. The 2-ethylhexanoate ligand fragments to lose carbon dioxide and 3-heptyl radical $[19,20]$. Two 3-heptyl radicals exchange hydrogen yielding heptane and heptene. The fate of one of the n-butyl ligands is to fragment leaving its oxygen with the titanium and forming a butyl radical. This radical abstracts a hydrogen from the alpha position of a second butoxide group generating butane. The remaining butoxide fragment, now deficient of a hydrogen atom rearranges and fragments to yield $\mathrm{CO}$ and propane. The titanium oxide formed is oxidized leading to the observed titanium dioxide.

Table 2 MS analysis of the volatile products formed by the photolysis of a film of titanium (IV) di-n-butoxide bis(2-ethylhexanoate)

\begin{tabular}{lll}
\hline $\mathrm{m} / \mathrm{z}$ & Fragment ions & $\begin{array}{l}\text { Parent } \\
\text { molecules }\end{array}$ \\
\hline 44 & $\mathrm{CO}_{2}^{+\bullet}$ & $\mathrm{CO}_{2}$ \\
$100,85,71$, & $\mathrm{C}_{7} \mathrm{H}_{16}^{+\bullet}, \mathrm{C}_{6} \mathrm{H}_{13}{ }^{+}, \mathrm{C}_{5} \mathrm{H}_{11}^{+}$, & $\mathrm{C}_{7} \mathrm{H}_{16}$ \\
$57,43,29,15$ & $\mathrm{C}_{4} \mathrm{H}_{9}^{+}, \mathrm{C}_{3} \mathrm{H}_{7}^{+}, \mathrm{C}_{2} \mathrm{H}_{5}^{+}, \mathrm{CH}_{3}^{+}$ & \\
$98,83,69,55$, & $\mathrm{C}_{7} \mathrm{H}_{14}^{+}, \mathrm{C}_{6} \mathrm{H}_{11}^{+}, \mathrm{C}_{5} \mathrm{H}_{9}^{+}$, & $\mathrm{C}_{7} \mathrm{H}_{14}$ \\
$41,27,15$ & $\mathrm{C}_{4} \mathrm{H}_{7}^{+}, \mathrm{C}_{3} \mathrm{H}_{5}{ }^{+}, \mathrm{C}_{2} \mathrm{H}_{3}^{+}, \mathrm{CH}_{3}^{+}$ & \\
$58,44,28$ & $\mathrm{C}_{4} \mathrm{H}_{10}{ }^{+}, \mathrm{C}_{3} \mathrm{H}_{8}{ }^{+\bullet}, \mathrm{CO}^{+\bullet}$ & $\mathrm{C}_{4} \mathrm{H}_{10}$, \\
& & $\mathrm{C}_{3} \mathrm{H}_{8}, \mathrm{CO}$ \\
\hline
\end{tabular}

$\mathrm{Ti}\left(\mathrm{OC}_{4} \mathrm{H}_{9}\right)_{2}\left(\mathrm{OOCCH}\left(\mathrm{C}_{2} \mathrm{H}_{5}\right) \mathrm{C}_{4} \mathrm{H}_{9}\right)_{2}+{ }^{1} / \mathrm{O}_{2} \stackrel{h v}{\longrightarrow}$ $\mathrm{TiO}_{2}+2 \mathrm{CO}_{2}+\mathrm{C}_{7} \mathrm{H}_{16}+\mathrm{C}_{7} \mathrm{H}_{14}+\mathrm{C}_{4} \mathrm{H}_{10}+\mathrm{C}_{3} \mathrm{H}_{8}+\mathrm{CO}$

Equation 3

In a similar experiment the photoreaction of a thin film of titanium (IV) di-n-butoxide bis(2ethylhexanoate) was also monitored by ellipsometry. The effect of photolysis for $0,2,4,8$, 18,36 and $766 \mathrm{~min}$ on the film thickness and the refractive index is shown in Figure 4. During the photolysis, the film thickness decreases to less than $1 / 5$ of its original value and the refractive index increases. Both of these processes occur with an apparent photolysis half life of 120 seconds.

These results are in keeping with the expectations from Equation 3. The photolysis results in the loss of a large portion of the molecular film as the ligands are lost, hence the reduction in thickness is approximately $1 / 6$ of its initial value. Being concomitant with this process, the film has a greater proportion of titanium and oxygen than the initial film, and as a result the dielectric constant of the film increases.

Similar results were obtained in the study of the photochemistry of titanium (IV) di-n-butoxide bis(2-ethyl-2-hydroxybutyrate). Photolysis resulted in the loss of absorption associated with the coordinated ligands and the formation of films of amorphous titanium oxide. The single most important deviation was that the photolysis of this complex led to the formation of an intermediate which was observable by FTIR spectroscopy. 


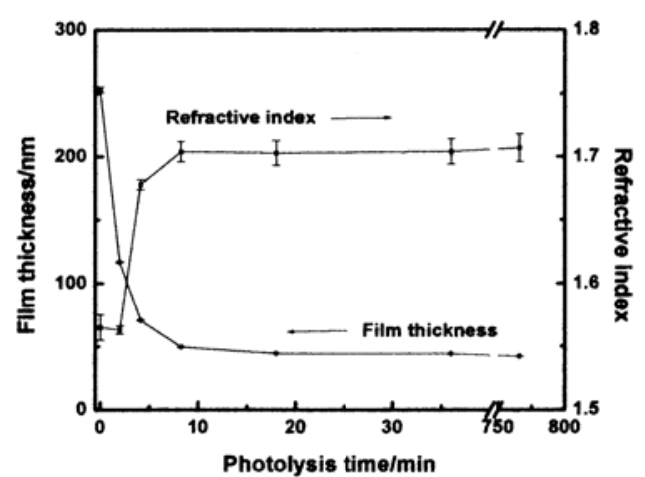

Figure 4 The effect of photolysis for $0,2,4,8,18,36$ and $766 \mathrm{~min}$ on the film thickness and the refractive index of a film of titanium (IV) di-n-butoxide bis(2ethylhexanoate) on a silicon chip

The most striking spectral feature of the intermediate was that the antisymmetric $v_{\text {as }}\left(\mathrm{CO}_{2}\right)$ stretching band was lost and replaced with a new band at lower energy. This is interpreted as a an indication that the photolysis resulted in the breakup of the polymer to form either shorter chains or monomers of titanium (IV) di-n-butoxide bis(2-ethyl-2-hydroxybutyrate). Similar behaviour has been reported in the past [20,21].

Following exhaustive photolysis the spectra indicated the loss of the coordinated ligands. The sample was then probed by Auger spectroscopy. This indicated an apparent ratio of oxygen to titanium to be $3.3: 1$. Given the calibration described above this result is consistent with the formation of titanium dioxide.

\subsubsection{Titanium (IV) diisopropoxide bis(diketonate)}

A thin film of titanium (IV) diisopropoxide bis(ethyl acetoacetate) was formed by spin coating a $\mathrm{CaF}_{2}$ disk with a hexane solution of the precursor. The FTIR spectrum was obtained and consisted of absorption bonds at 1634, 1610, 1526, 1476, 1446, $1414,1368,1280,1270,1170$ and $1125 \mathrm{~cm}^{-1}$. The spectrum is shown in Figure 5.

By analogy with IR assignments of metal 2,4pentanedionates and metal alkoxides $[14,15]$, the absorption bands are assigned as follows. The bands at 1634 and $1610 \mathrm{~cm}^{-1}$ are assigned to $v(\mathrm{C}-\mathrm{C})$ coupled with $v(\mathrm{C}-\mathrm{O})$ of the diketonate. The band at $1526 \mathrm{~cm}^{-1}$ is associated with $v(\mathrm{C}-\mathrm{O})$ coupled with $v(\mathrm{C}-\mathrm{C})$. The bands at 1476,1446 , 1414 , and $1368 \mathrm{~cm}^{-1}$ are assigned to $\delta(\mathrm{CH})$ and $\delta$ $\left(\mathrm{CH}_{3}\right)$ mixed with $v(\mathrm{C}-\mathrm{C})$ and $v(\mathrm{C}-\mathrm{O})$. The bands at 1280 and $1270 \mathrm{~cm}^{-1}$ are associated with $v(\mathrm{COC})$ from the ester group mixed with $v\left(\mathrm{C}-\mathrm{CH}_{3}\right)$ and
$v(C-\mathrm{C})[14,22]$. . The absorbance at 1170 and $1125 \mathrm{~cm}^{-1}$ is assigned to the overlap of $v\left(\mathrm{C}-\mathrm{CH}_{3}\right)$ and $v(\mathrm{C}-\mathrm{O})$ from both the isopropoxy ligands and ethoxy groups.

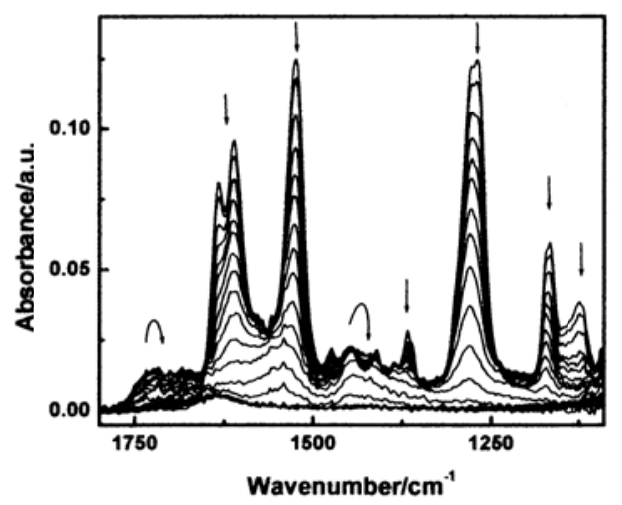

Figure 5 The effect of photolysis for $0,10,30,60,90$, $120,180,240,330,450,600,780,1020,1320,1800$, and 2160 seconds on the FTIR spectrum of a sample of titanium (IV) diisopropoxide bis(ethyl acetoacetate) on a calcium fluoride disc

Upon photolysis, the intensities of absorption bands at 1634, 1610, 1526, 1476, 1368, 1280, 1270,1170 and $1125 \mathrm{~cm}^{-1}$ all decrease in intensity. They do not however decrease in proportion to their original intensity. As the photolysis progresses, it becomes apparent that the new absorption bands at 1725 and $1438 \mathrm{~cm}^{-1}$ appear. These bands appear to reach a maximum intensity at about 330 seconds of photolysis. Continued photolysis result in the loss of intensity associated with all bands associated with coordinated ligand.

The formation of transient absorption bands and the non proportional loss of the bands associated with the starting material are indicative of the formation of an intermediate. By examination of the spectral changes, the intermediate appears to have bands indicative of the presence of the ethyl acetoacetate ligand but to have lost features associated with the isopropoxide ligand. The bands at 1725 and $1438 \mathrm{~cm}^{-1}$ are presumably associated with $v(\mathrm{C}=\mathrm{O})$ and $v(\mathrm{OCO})$ from the ester groups, respectively.

Following exhaustive photolysis, all bands associated with the intermediate are lost and the film has no absorptions consistent with a molecular complex or the presence of complex ligands. The overall reaction is believed to be as described in Equation 4.

$$
\begin{aligned}
& \mathrm{Ti}\left(\mathrm{OC}_{3} \mathrm{H}_{7}\right)_{2}\left(\mathrm{OC}\left(\mathrm{CH}_{3}\right) \mathrm{CHCOOC}_{2} \mathrm{H}_{5}\right)_{2}+\mathrm{O}_{2} \stackrel{h v}{\longrightarrow} \\
& \mathrm{TiO}_{2 \text { (amorphous) }}+\text { organic by-products }
\end{aligned}
$$


Similar experiments have been reported previously $[11,13]$ in the study of the preparation of carbon-free amorphous titanium oxide films from titanium (IV) diisopropoxide bis(2,4pentanedionate). Since the complex studies here indicated the presence of an intermediate, while our previous reports of titanium (IV) diisopropoxide bis(2,4-pentanedionate) did not reexamine the spectral changes associated with the photolysis of titanium (IV) diisopropoxide bis(2,4pentanedionate).

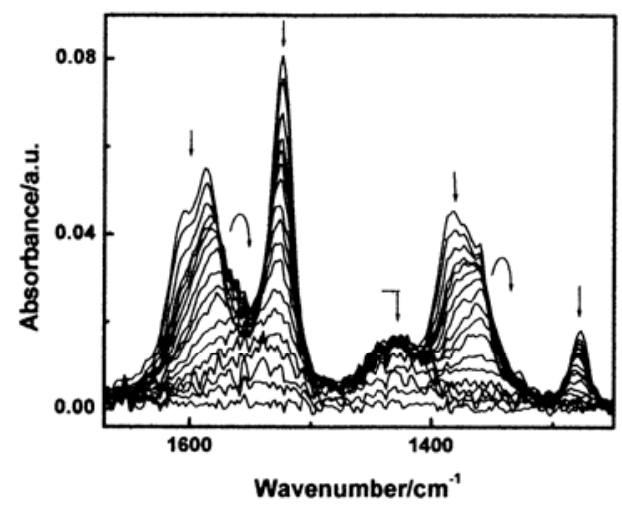

Figure 6 The effect of photolysis for $0,10,30,60,90$, $120,180,300,420,600,780,1020,1320,1680,2100$, 2580,3120 , and 3720 seconds on the FTIR spectrum of a sample of titanium (IV) diisopropoxide bis(2,4pentanedionate) on a silicon chip

The spectra associated with the photolysis of a thin film of titanium (IV) diisopropoxide bis(2,4pentanedionate) are shown in Figure 6. The signal to noise in this spectrum is far better than previously observed. The photolysis results in the loss of intensity of absorption bands associated with the starting material and it is evident from the growth of absorption bands at 1560, 1425 and $1340 \mathrm{~cm}^{-1}$.

The spectral changes are similar to that found for titanium (IV) diisopropoxide bis(ethyl acetoacetate) and we believe that the interpretation is the same here.

\subsection{Positive and Negative Lithography}

3.3.1. Negative photolithography of titanium (IV) di-n-butoxide bis(2-ethylhexanoate)

A thin film of titanium (IV) di-n-butoxide bis(2-ethylhexanoate) was prepared on a three-inch wafer. The film was baked at $90{ }^{\circ} \mathrm{C}$ for 5 minutes and then photo patterned with a Kasper 2001 Aligner. The surface was spin developed with hexanes and the resultant features are shown in Figure 7(a). Another thin film of titanium (IV) di- n-butoxide bis(2-ethylhexanoate) was prepared and exposed through a lithography mask in contact with the surface. The surface was developed with methyl isobutyl ketone and the resultant features are shown in Figure 7(b). The features were then observed by optical microscopy and found to consist of 1 micron lines and spaces. In Figure 7, the deposited titanium dioxide is in the darker areas which were exposed to the light.

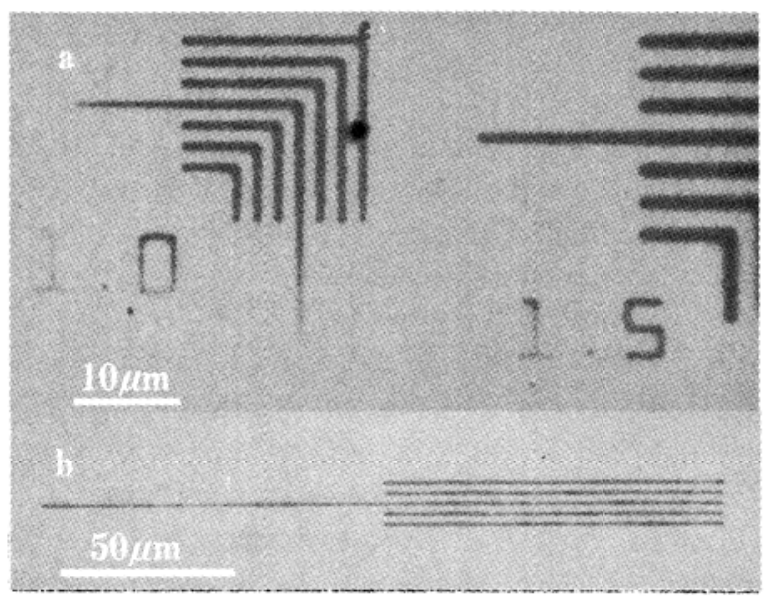

Figure 7 Patterns of titanium oxide prepared from titanium (IV) di-n-butoxide bis(2-ethylhexanoate) by negative lithographic photochemical metal organic deposition

No developer was found suitable for the positive photolithography of titanium (IV) di-nbutoxide bis(2-ethylhexanoate) films. This is presumably, because photolysis of titanium (IV) di-n-butoxide bis(2-ethylhexanoate) results in only titanium oxide and there is no suitable solvent that dissolves titanium oxide but not the complex.

3.3.2. Negative and positive photolithography of titanium (IV) di-n-butoxide bis(2-ethyl-2hydroxybutyrate)

A thin film of titanium (IV) di-n-butoxide bis(2-ethyl-2-hydroxybutyrate) was prepared by spin coating from a solution of methyl isobutyl ketone and anhydrous ethanol (50\%:50\% wt mixture). The sample was exposed for 10 minutes in contact mode. The sample could be developed with methyl isobutyl ketone, yielding the image of negative lithography shown in Figure 8(a). Alternatively, development with distilled water led to the formation of a positive pattern which upon blanket exposure was converted to titanium dioxide. The positive pattern is shown in Figure 8(b). 


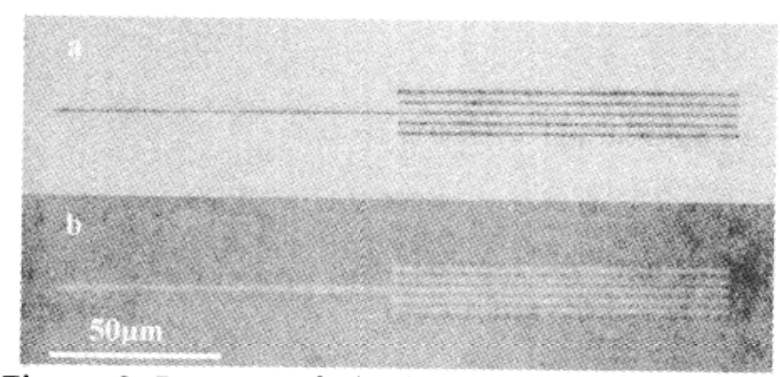

Figure 8 Patterns of titanium oxide prepared from titanium (IV) di-n-butoxide bis(2-ethyl-2hydroxybutyrate) by negative (a) and positive (b) lithographic photochemical metal organic deposition.

\subsubsection{Negative and positive photolithography of} titanium (IV) diisopropoxide bis(ethyl acetoacetate) and titanium (IV) diisopropoxide bis(2,4-pentanedionate)

Thin films of titanium (IV) diisopropoxide bis(ethyl acetoacetate) were spin coated from methyl isobutyl ketone solutions and exposed for 30 minutes under contact lithography conditions. Development of the film with methyl isobutyl ketone led to the negative deposition of structures with a feature size of about one micron. A similar experiment was conducted on a film deposited from a hexane solution, with an exposure time of 15 minutes. The film was then exposed to hexane for about 5 seconds and then developed with methanol. The resultant surface consisted of structures with a feature size of 1 micron. The hexane acted as a fixer and resulted in a more easily obtained image. The process could also be done without the use of the fixer but this often resulted in some degradation of the image.

A film of titanium (IV) diisopropoxide bis(2,4pentanedionate) was deposited by spin coating a methyl isobutyl ketone solution. Contact lithography with a 40 minute exposure was followed by development with methyl isobutyl ketone and resulted in the formation of 1.5 micron feature size lines.

A similar experiment was done, however, the exposure time was limited to 4 minutes and the development was done with water. The sample was then subjected to a blanket exposure to convert the material still on the surface to titanium dioxide. The positive pattern showed features of 1.5 micron size.

\section{Discussion}

The results of the lithography experiments presented here indicated that only systems, where an intermediate was formed, made it possible to perform positive lithography while in all cases we were able to demonstrate negative lithography.

The negative lithography is generally a result of the photoconversion of all the precursor complexes studied here to titanium dioxide. The product, titanium dioxide, is not soluble in the non-reactive developing solvents studied here and so long exposure times were always able to convert the exposed regions into insoluble titanium dioxide. Subsequent development resulted in the removal of the more soluble precursor molecules and a negative pattern.

Positive lithography in contrast was generally conducted with shorter exposure time. Under these conditions the exposed region is a mixture of the precursor molecules and the titanium dioxide. The more polar developer was then used and the exposed region which consisted of both the precursor molecules and the photoproduced oxide was more readily attacked by the polar solvent than the less polar unexposed regions of the film which were composed only of the less polar precursor.

Interestingly, films of titanium (IV) di-nbutoxide bis(2-ethylhexanoate) were the single example presented here, with which we were unable to demonstrate positive lithography. It is also the single system that did not present a observable intermediate in the FTIR study of the reaction. It is tempting to speculate that the intermediate in some way facilitated the formation of the positive image. This is unlikely however. Recall that this complex was one which did not appear to form polymers by association of the precursor within the thin film. The partial photolysis of this film should result in a mixture of the precursor with titanium dioxide. In contrast films of di-n-butoxide bis(2-ethyl-2hydroxybutyrate) upon photolysis rapidly depolymerized. This suggests that, in the exposed region, the film consisted of largely the monomeric di-n-butoxide bis(2-ethyl-2hydroxybutyrate) and titanium dioxide. The presence of the intermediate did not fundamentally alter the nature of the exposed region.

As a result, we believe that the successful demonstration of positive lithography in the systems, where intermediate formation is evident, is coincidental. It should be possible to perform positive lithography on systems where no intermediate is apparent as well.

\section{Conclusions}

A series of titanium (IV) complexes were prepared and their utility in photochemical metal 
organic deposition was assessed. We were able to demonstrate both positive and negative lithography from here of the precursors studied. The choice of positive vs negative lithography for two of the systems was controlled by a combination of the exposure time, while the solvent in the third system was controlled entirely by the choice of the developing solvent. One of the limitations of negative lithography by PMOD has been the comparatively large doses required for photo patterning. The results presented here suggest that photo patterning by positive lithography may be possible with significantly smaller doses than that used in negative lithography. Studies to quantify this effect are now underway.

\section{Acknowledgement}

The authors thank Natural Sciences and Engineering Research Council of Canada and EKC Tech. for funding. The authors thank Mr. Ken Myrtle for assistance in obtaining Auger electron spectra.

\section{References}

1. M. D. Stamate, Thin Solid Films. 372 (2000), 246-249

2. J. Zhang, J. S. Yuan, Y. Ma and A. S. Oates, Solid-State Electronics. 44 (2000), 2165-2170

3. N. Kaliwoh, J-Y. Zhang and I. W. Boyd, Appl. Sur. Sci. 186 (2002), 241-245

4. A. Rahtu, M. Ritala and M. Leskelä, Chem. Mater. 13(5) (2001), 1528-1532

5. A. Fujishima, T. N. Rao, and D. A. Tryk, $J$. Photochem. Photobio. C: Photochemistry Reviews. 1 (2000), 1-21

6. K-W. Kim, E-H. Lee, Y-J. Kim, M-H. Lee, KH. Kim and D-W. Shin, J. Photochem.

Photobio. A: Chemistry. 159 (2003), 301-310

7. B. Karunagaran, R.T. Rajendra Kumar, D. Mangalaraj, Sa. K. Narayandass and G. Mohan Rao, Cryst. Res. Technol. 37(12) (2002), 12851292

8. T. D. Flaim, D. J. Guerrero, M. R. Fowler, W. J. James, V. Petrovsky and H. U. Anderson, USA Patent No. 6, 303,270 (2001)

9. R. H. Hill, P. J. Roman, S. Suh and X. Zhang, USA Patent Application, Application No.
10/377,533 (Filed USA Feb. 26, 2003), Publication number: US 2003-0190820 A1, Oct. 9, 2003

10. R. H. Hill, B. J. Palmer, Jr. Avey, A. Alfred, S. L. Blair, C-H. W. Chu, M. Gao and W. L. Law, USA Patent No. 5,534,312 (1996)

11. S. L. Blair and R. H. Hill, ACS Symposium Series 706 (1998), 53-66

12. B. J. Palmer, A. Becalska, T. W. H. Ho and R. H. Hill, J. Mater. Sci. 28 (1993), 6013-6020

13. H. J. Zhu and R. H. Hill, J. Photochem. Photobio. A: Chemistry. 147 (2002), 127-133

14. K. Nakamoto, "Infrared and Raman Spectra of Inorganic and Coordination Compounds, $4^{\text {th }}$ Edition", A Wiley-Interscience Publication, JOHN WILEY \& SONS, Toronto 1986

15. D. C. Bradley, R. C. Mehrotra, I. P. Rothwell and A. Singh, "Alkoxo and Aryloxo Derivatives of Metals", ACADEMIC PRESS, San Diego - San Francisco - New York · Boston · London · Sydney · Tokyo, 2001, p.7377 and p.117-123

16. T. V. Rogova, M. I. Yanovskaya, D. U. Grudtsyna, Yu. D. Grudtyn, and E. P. Kovsman, Rus. J. General Chem. 67(7) (1997), 1068-1077

17. L. E. Davis, N. C. MacDonald, P. W. Palmberg, G. E. Rich, and R. E. Weber, "Handbook of Auger Electron Spectroscopy, $2^{\text {nd }}$ Edition", Perkin-Elmer Corp., Eden Prairie, 1976

18. M. C. Morris, H. F. McMurdie, E. H. Evans, J. de Groot, B. Paretzkin, H. E. Swanson and S. J. Carmel, "JCPDS National Bureau of Standards, $1^{\text {st }}$ ed", the JCPDS, Swarthmore, Pennsylvania, 1976, file No. 21-1272

19. L. S. Andronic and R. H. Hill, J. Photoche. Photobio. A: Chemistry. 152 (2002), 259-265

20. H. J. Zhu and R. H. Hill, J. Non-Cryst. Solids. 311 (2002), 174-184

21. W. L. Law and R. H. Hill, Mater. Res. Bull. 33(1) (1998), 69-80

22. S.-I. Jang, B.-C. Choi and H. M. Jang, J. Mater. Res. 12(5) (1997), 1327-1334 